\title{
FIXED-POINT ITERATION PROCESSES FOR NON-LIPSCHITZIAN MAPPINGS OF ASYMPTOTICALLY QUASI-NONEXPANSIVE TYPE
}

\author{
DAYA RAM SAHU and JONG SOO JUNG
}

Received 5 February 2003

We study convergences of Mann and Ishikawa iteration processes for mappings of asymptotically quasi-nonexpansive type in Banach spaces.

2000 Mathematics Subject Classification: 47H09, 47H10.

1. Introduction and preliminaries. Let $D$ be a nonempty subset of a real Banach space $X$ and $T: D \rightarrow D$ a nonlinear mapping. The mapping $T$ is said to be asymptotically quasi-nonexpansive (see [5]) if $F(T) \neq \varnothing$ and there exists a sequence $\left\{k_{n}\right\}$ in $[0, \infty)$ with $\lim _{n \rightarrow \infty} k_{n}=0$ such that

$$
\left\|T^{n} x-p\right\| \leq\left(1+k_{n}\right)\|x-p\|
$$

for all $x \in D, p \in F(T)$, and $n \in \mathbb{N}$. The mapping $T$ is said to be asymptotically nonexpansive (see [3]) if there exists a sequence $\left\{k_{n}\right\}$ in $[0, \infty)$ with $\lim _{n \rightarrow \infty} k_{n}=$ 0 such that

$$
\left\|T^{n} x-T^{n} y\right\| \leq\left(1+k_{n}\right)\|x-y\|
$$

for all $x, y \in D$ and $n \in \mathbb{N}$. The mapping $T$ is said to be a mapping of asymptotically nonexpansive type [4] if

$$
\limsup _{n \rightarrow \infty} \sup _{x \in D}\left(\left\|T^{n} x-T^{n} y\right\|-\|x-y\|\right) \leq 0
$$

for any $y \in D$.

In 1973, Petryshyn and Williamson [7] gave necessary and sufficient conditions for Mann iterative sequence to converge to fixed points of quasi-nonexpansive mappings. In 1997, Ghosh and Debnath [2] extended the results of [7] and gave the necessary and sufficient conditions for Ishikawa iterative sequence to converge to fixed points for quasi-nonexpansive mappings.

Recently, Liu [5] extended results of [2, 7] and gave the necessary and sufficient conditions for Ishikawa iterative sequence to converge to fixed points of asymptotically quasi-nonexpansive mappings. 
First, we introduce the concept of class of mappings of asymptotically quasinonexpansive type: the mapping $T$ is said to be a mapping of asymptotically quasi-nonexpansive type if $F(T) \neq \varnothing$ and

$$
\limsup _{n \rightarrow \infty} \sup _{x \in D}\left(\left\|T^{n} x-p\right\|-\|x-p\|\right) \leq 0 \quad \text { for any } p \in F(T) .
$$

REMARK 1.1. If $T$ is a mapping of asymptotically nonexpansive type with $F(T) \neq \varnothing$, then $T$ is a mapping of asymptotically quasi-nonexpansive type.

REMARK 1.2. If $D$ is bounded and $T$ is an asymptotically quasi-nonexpansive mapping, then $T$ is a mapping of asymptotically quasi-nonexpansive type. In fact, if $T$ is an asymptotically quasi-nonexpansive mapping, then there exists a sequence $\left\{k_{n}\right\}$ in $[0, \infty)$ with $\lim _{n \rightarrow \infty} k_{n}=0$ such that

$$
\left\|T^{n} x-p\right\| \leq\left(1+k_{n}\right)\|x-p\|
$$

for all $x \in D, p \in F(T)$, and $n \in \mathbb{N}$, which implies

$$
\sup _{x \in D}\left\{\left\|T^{n} x-T^{n} y\right\|-\|x-y\|\right\} \leq k_{n} \cdot \operatorname{diam} D
$$

for any $y \in F(T)$ and $n \in \mathbb{N}$. Hence

$$
\limsup _{n \rightarrow \infty} \sup _{x \in D}\left(\left\|T^{n} x-T^{n} y\right\|-\|x-y\|\right) \leq 0 \quad \text { for any } y \in F(T) .
$$

We observe from Remarks 1.1 and 1.2 that the class of mappings of asymptotically nonexpansive type is an intermediate class between the class of mappings of asymptotically quasi-nonexpansive type and that of mappings of asymptotically nonexpansive type with nonempty fixed-point sets. Let

$C_{1}=\{T: T: D \longrightarrow D$ is a nonexpansive mapping $\}$,

$C_{2}=\{T: T: D \longrightarrow D$ is a quasi-nonexpansive mapping $\}$,

$C_{3}=\{T: T: D \longrightarrow D$ is an asymptotically nonexpansive mapping $\}$,

$C_{4}=\{T: T: D \longrightarrow D$ is an asymptotically quasi-nonexpansive mapping $\}$,

$C_{5}=\{T: T: D \longrightarrow D$ is a mapping of asymptotically nonexpansive type $\}$,

$C_{6}=\{T: T: D \longrightarrow D$ is a mapping of asymptotically quasi-nonexpansive type $\}$.

Then we have the following implications:

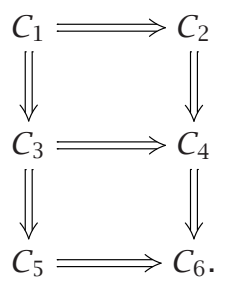


In this paper, we are mainly interested in the problem of approximation of fixed points of the more general class of mappings of asymptotically quasinonexpansive type than that of asymptotically quasi-nonexpansive mappings. The purpose of this paper is to continue discussion concerning convergence of Mann and Ishikawa iteration processes for mappings of asymptotically quasinonexpansive type in Banach spaces. We give necessary and sufficient conditions for the Mann and Ishikawa iteration processes to converge to fixed points of mappings of asymptotically quasi-nonexpansive type. Further, we obtain extensions of various results obtained quite recently by Deng [1], Ghosh and Denath [2], Liu [5], and Tan and Xu [9, 10] to more general types of space as well as families of operators.

We say that a Banach space $X$ satisfies Opial's condition [6] if, for each sequence $\left\{x_{n}\right\}$ in $X$ weakly convergent to a point $x$ and for all $y \neq x$,

$$
\liminf _{n \rightarrow \infty}\left\|x_{n}-x\right\|<\liminf _{n \rightarrow \infty}\left\|x_{n}-y\right\|
$$

The examples of Banach spaces which satisfy Opial's condition are Hilbert spaces, and all $L^{p}[0,2 \pi]$ with $1<p \neq 2$ fail to satisfy Opial's condition [6].

Let $D$ be a nonempty closed convex subset of a Banach space $X$. Then $I-T$ is demiclosed at zero if, for any sequence $\left\{x_{n}\right\}$ in $D$, condition $x_{n} \rightarrow x$ weakly and $\lim _{n \rightarrow \infty}\left\|x_{n}-T x_{n}\right\|=0$ implies $(I-T) x=0$.

2. Main results. In this section, we establish some weak and strong convergences for mappings of asymptotically quasi-nonexpansive type in Banach spaces.

LEMMA 2.1. Let $D$ be a nonempty subset of a normed space $X$ and let $T$ : $D \rightarrow E$ be a mapping of asymptotically quasi-nonexpansive type. For two given real sequences $\left\{\alpha_{n}\right\}$ and $\left\{\beta_{n}\right\}$ in $[0,1]$, let a sequence $\left\{x_{n}\right\}$ in $D$ be defined by

$$
\begin{gathered}
x_{n+1}=\left(1-\alpha_{n}\right) x_{n}+\alpha_{n} T y_{n}, \\
y_{n}=\left(1-\beta_{n}\right) x_{n}+\beta_{n} T x_{n}, \quad n=1,2, \ldots .
\end{gathered}
$$

If $p$ is a fixed point of $T$, then

(a) $\left\|x_{n+1}-p\right\| \leq\left\|x_{n}-p\right\|+\left(1+\beta_{n}\right) \sup _{x \in D}\left(\left\|T^{n} x-p\right\|-\|x-p\|\right), n=$ $1,2, \ldots$,

(b) $\lim _{n \rightarrow \infty}\left\|x_{n}-p\right\|$ exists.

Proof. Let $p$ be a fixed point of $T$.

(a) From (2.1), we have

$$
\begin{aligned}
\left\|x_{n+1}-p\right\| \leq & \left(1-\alpha_{n}\right)\left\|x_{n}-p\right\|+\alpha_{n}\left\|T^{n} y_{n}-p\right\| \\
\leq & \left(1-\alpha_{n}\right)\left\|x_{n}-p\right\|+\alpha_{n}\left(\left\|T^{n} y_{n}-p\right\|\right. \\
& -\|y-p\|)+\alpha_{n}\left\|y_{n}-p\right\|
\end{aligned}
$$




$$
\begin{aligned}
\leq & \left(1-\alpha_{n}\right)\left\|x_{n}-p\right\|+\left(\left\|T^{n} y_{n}-p\right\|-\left\|y_{n}-p\right\|\right) \\
& +\alpha_{n}\left(\left(1-\beta_{n}\right)\left\|x_{n}-p\right\|+\beta_{n}\left\|T^{n} x_{n}-p\right\|\right) \\
\leq & \left\|x_{n}-p\right\|+\left(\left\|T^{n} y_{n}-p\right\|-\left\|y_{n}-p\right\|\right) \\
& +\beta_{n}\left(\left\|T^{n} x_{n}-p\right\|-\left\|x_{n}-p\right\|\right) \\
\leq & \left\|x_{n}-p\right\|+\left(1+\beta_{n}\right) \sup _{x \in D}\left(\left\|T^{n} x-p\right\|-\|x-p\|\right) .
\end{aligned}
$$

(b) For $m, n \in \mathbb{N}$, we have

$$
\begin{aligned}
\left\|x_{n+m}-p\right\| & \leq\left\|x_{n+m-1}-p\right\|+2 \sup _{x \in D}\left(\left\|T^{n+m-1} x-p\right\|-\|x-p\|\right) \\
& \leq\left\|x_{n+m-1}-p\right\|+2 \sup _{x \in D}\left(\left\|T^{m} x-p\right\|-\|x-p\|\right) \\
& \leq\left\|x_{n+m-2}-p\right\|+4 \sup _{x \in D}\left(\left\|T^{m} x-p\right\|-\|x-p\|\right) \\
& \leq \cdots \leq\left\|x_{n}-p\right\|+2 n \sup _{x \in D}\left(\left\|T^{m} x-p\right\|-\|x-p\|\right) .
\end{aligned}
$$

Hence, for $n \in \mathbb{N}$,

$$
\begin{aligned}
\limsup _{m \rightarrow \infty}\left\|x_{m}-p\right\| & \leq\left\|x_{n}-p\right\|+2 n \limsup _{m \rightarrow \infty}\left(\left\|T^{m} x-p\right\|-\|x-p\|\right) \\
& \leq\left\|x_{n}-p\right\| .
\end{aligned}
$$

It follows that

$$
\limsup _{m \rightarrow \infty}\left\|x_{m}-p\right\| \leq \liminf _{n \rightarrow \infty}\left\|x_{n}-p\right\|
$$

Thus $\lim _{n \rightarrow \infty}\left\|x_{n}-p\right\|$ exists.

LEMMA 2.2. Let $D$ and $T$ be as in Lemma 2.1. For a given real sequence $\left\{\alpha_{n}\right\}$ in $[0,1]$, let a sequence $\left\{x_{n}\right\}$ in $D$ be defined by

$$
x_{n+1}=\left(1-\alpha_{n}\right) x_{n}+\alpha_{n} T^{n} x_{n}, \quad n=1,2, \ldots
$$

If $p$ is a fixed point of $T$, then

(a) $\left\|x_{n+1}-p\right\| \leq\left\|x_{n}-p\right\|+\sup _{x \in D}\left(\left\|T^{n} x-p\right\|-\|x-p\|\right), n=1,2, \ldots$,

(b) $\lim _{n \rightarrow \infty}\left\|x_{n}-p\right\|$ exists.

THEOREM 2.3. Let $X$ be a Banach space which satisfies Opial's condition and let $D$ be a weakly compact subset of $X$. Let $T$ and $\left\{x_{n}\right\}$ be as in Lemma 2.1. Suppose that $T$ has a fixed point, $I-T$ is demiclosed at zero, and $\left\{x_{n}\right\}$ is an approximating fixed-point sequence for $T$, that is, $\lim _{n \rightarrow \infty}\left\|x_{n}-T x_{n}\right\|=0$. Then $\left\{x_{n}\right\}$ converges weakly to a fixed point of $T$.

Proof. First, we show that $\omega_{w}\left(x_{n}\right) \subset F(T)$. Let $x_{n_{k}} \rightarrow x$ weakly. By assumption, we have $\lim _{n \rightarrow \infty}\left\|x_{n}-T x_{n}\right\|=0$. Since $I-T$ is demiclosed at zero, 
$x \in F(T)$. By Opial's condition, $\left\{x_{n}\right\}$ possesses only one weak limit point, that is, $\left\{x_{n}\right\}$ converges weakly to a fixed point of $T$.

THEOREM 2.4. Let $X$ be a Banach space which satisfies Opial's condition and let $D$ be a weakly compact subset of $X$. Let $T$ and $\left\{x_{n}\right\}$ be as in Lemma 2.2. Suppose that $T$ has a fixed point, $I-T$ is demiclosed at zero, and $\left\{x_{n}\right\}$ is an approximating fixed-point sequence for $T$, that is, $\lim _{n \rightarrow \infty}\left\|x_{n}-T x_{n}\right\|=0$. Then $\left\{x_{n}\right\}$ converges weakly to a fixed point of $T$.

REMARK 2.5. Theorem 2.3 improves Theorem 2 of Deng [1] for mappings of asymptotically quasi-nonexpansive type. Theorem 2.4 generalizes Theorem 2.1 of Schu [8].

THEOREM 2.6. Let $D$ be a closed subset of Banach space, let $T: D \rightarrow D$ be a mapping of asymptotically quasi-nonexpansive type, and $F(T)$ be nonempty closed set. For two given real sequences $\left\{\alpha_{n}\right\}$ and $\{\beta\}$ in $[0,1]$, let the Ishikawa iterative sequence $\left\{x_{n}\right\}$ in $D$ be defined by (2.1). Then $\left\{x_{n}\right\}$ converges strongly to a fixed point of $T$ if and only if $\liminf _{n} d\left(x_{n}, F(T)\right)=0$.

Proof. Let $\left\{x_{n}\right\}$ converge strongly to a point $z \in F(T)$. Then $\lim _{n} d\left(x_{n}\right.$, $F(T))=0$. Conversely, suppose $\liminf _{n} d\left(x_{n}, F(T)\right)=0$. From Lemma 2.1(a),

$$
\left\|x_{n+1}-p\right\| \leq\left\|x_{n}-p\right\|+2 \sup _{x \in D}\left(\left\|T^{n} x-p\right\|-\|x-p\|\right)
$$

for any $n \in \mathbb{N}$ and $p \in F(T)$. Since $T$ is a mapping of asymptotically quasinonexpansive type, we have

$$
\limsup _{n}\left\{\sup _{x \in D}\left(\left\|T^{k} x-p\right\|-\|x-p\|\right)\right\} \leq 0
$$

Hence, there exists a positive integer $n_{0}$ and a sequence $\left\{a_{n}\right\}$ of positive real numbers with $\lim _{n} a_{n}=0$ such that

$$
\sup _{k \geq n}\left\{\sup _{x \in D}\left(\left\|T^{k} x-p\right\|-\|x-p\|\right)\right\} \leq a_{n}
$$

for any $n \geq n_{0}$. Without loss of generality, we can assume that $a_{n}=1 / 2 n^{2}$. Hence,

$$
\sup _{k \geq n}\left\{\sup _{x \in D}\left(\left\|T^{k} x-p\right\|-\|x-p\|\right)\right\} \leq \frac{1}{2 n^{2}}
$$

for any $n \geq n_{0}$. It follows from (2.7) that

$$
\left\|x_{n+1}-p\right\| \leq\left\|x_{n}-p\right\|+\frac{1}{n^{2}}
$$


for all $n \geq n_{0}$, that is,

$$
d\left(x_{n+1}, F(T)\right) \leq d\left(x_{n}, F(T)\right)+\frac{1}{n^{2}}
$$

for all $n \geq n_{0}$. Hence for $n, m \geq n_{0}$, we have

$$
d\left(x_{n+m}, F(T)\right) \leq d\left(x_{n}, F(T)\right)+\sum_{i=n}^{n+m-1} \frac{1}{i^{2}} .
$$

Using [10, Lemma 1, page 303], we obtain that $\lim _{n} d\left(x_{n}, F(T)\right)$ exists, and it follows from $\liminf _{n} d\left(x_{n}, F(T)\right)=0$ that $\lim _{n} d\left(x_{n}, F(T)\right)=0$. Thus, $\lim _{n} d\left(x_{n}, F(T)\right)=0$. For each $\varepsilon>0$, there exists a natural number $m_{0}$ such that

$$
d\left(x_{n}, F(T)\right)<\frac{\varepsilon}{3}
$$

for all $n \geq m_{0}$. Then there exists a $p^{\prime} \in F(T)$ such that $d\left(x_{n}, p^{\prime}\right)<\varepsilon / 2$ for all $n \geq m_{0}$. If $n, m \geq m_{0}$, then

$$
d\left(x_{n}, x_{m}\right) \leq d\left(x_{n}, p^{\prime}\right)+d\left(p^{\prime}, x_{m}\right) \leq \frac{\varepsilon}{2}+\frac{\varepsilon}{2}=\varepsilon .
$$

This shows that $\left\{x_{n}\right\}$ is a Cauchy sequence in $D$. Let $\lim _{n} x_{n}=v \in D$. Since $F(T) \subset D$ is closed and $\lim _{n} d\left(x_{n}, F(T)\right)=0$, we conclude that $v \in F(T)$. This completes the proof.

As a consequence of Theorem 2.6, we obtain the following result.

THeOrem 2.7. Let $D$ be a closed subset of Banach space, let $T: D \rightarrow D$ be a mapping of asymptotically quasi-nonexpansive type, and let $F(T)$ be a nonempty closed set. For a given sequence $\left\{\alpha_{n}\right\}$ in $[0,1]$, let the Mann iterative sequence $\left\{x_{n}\right\}$ in $D$ be defined by (2.6). Then $\left\{x_{n}\right\}$ converges strongly to a fixed point of $T$ if and only if $\liminf _{n} d\left(x_{n}, F(T)\right)=0$.

REMARK 2.8. Theorems 2.6 and 2.7 extend corresponding results of Ghosh and Debnath [2], Liu [5], and Petryshyn and Williamson [7] from quasi-nonexpansive or asymptotically quasi-nonexpansive mapping to large class of nonLipschitzian mappings.

ACKNOwLEDGment. The first author wishes to acknowledge the financial support of the Department of Science and Technology, India, made in the program year 2002-2003, Project No. SR/FTP/MS-15. The second author was supported by Korea Research Foundation Grant KRF-2000-DP0013.

\section{REFERENCES}

[1] L. Deng, Convergence of the Ishikawa iteration process for nonexpansive mappings, J. Math. Anal. Appl. 199 (1996), no. 3, 769-775. 
[2] M. K. Ghosh and L. Debnath, Convergence of Ishikawa iterates of quasinonexpansive mappings, J. Math. Anal. Appl. 207 (1997), no. 1, 96-103.

[3] K. Goebel and W. A. Kirk, A fixed point theorem for asymptotically nonexpansive mappings, Proc. Amer. Math. Soc. 35 (1972), 171-174.

[4] W. A. Kirk, Fixed point theorems for non-Lipschitzian mappings of asymptotically nonexpansive type, Israel J. Math. 17 (1974), 339-346.

[5] Q. Liu, Iterative sequences for asymptotically quasi-nonexpansive mappings, J. Math. Anal. Appl. 259 (2001), no. 1, 1-7.

[6] Z. Opial, Weak convergence of the sequence of successive approximations for nonexpansive mappings, Bull. Amer. Math. Soc. 73 (1967), 591-597.

[7] W. V. Petryshyn and T. E. Williamson Jr., Strong and weak convergence of the sequence of successive approximations for quasi-nonexpansive mappings, J. Math. Anal. Appl. 43 (1973), 459-497.

[8] J. Schu, Weak and strong convergence to fixed points of asymptotically nonexpansive mappings, Bull. Austral. Math. Soc. 43 (1991), no. 1, 153-159.

[9] K.-K. Tan and H. K. Xu, Approximating fixed points of nonexpansive mappings by the Ishikawa iteration process, J. Math. Anal. Appl. 178 (1993), no. 2, 301-308.

[10] _ Fixed point iteration processes for asymptotically nonexpansive mappings, Proc. Amer. Math. Soc. 122 (1994), no. 3, 733-739.

Daya Ram Sahu: Department of Applied Mathematics, Shri Shankaracharya College of Engineering, Junwani, Bhilai 490 020, India

E-mail address: sahudr@rediffmai 1.com

Jong Soo Jung: Department of Mathematics, Dong-A University, Pusan 604-714, Korea

E-mail address: jungjs@mai 1.donga.ac.kr 


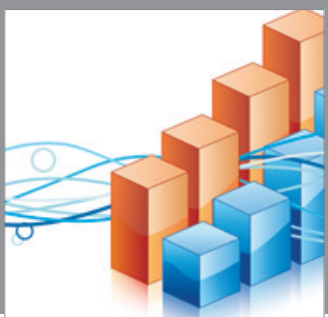

Advances in

Operations Research

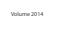

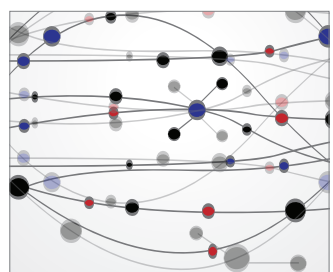

\section{The Scientific} World Journal
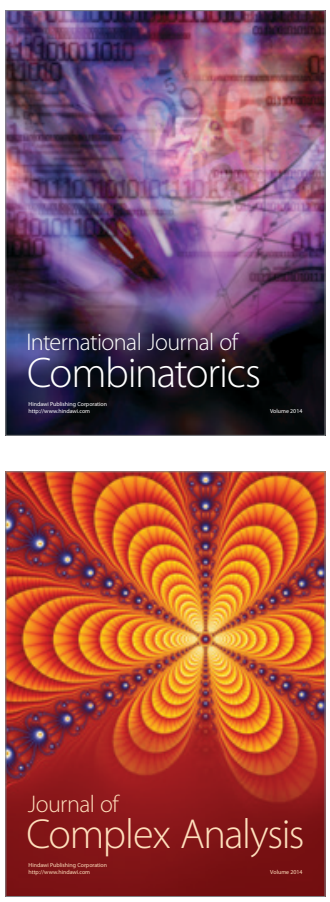

International Journal of

Mathematics and

Mathematical

Sciences
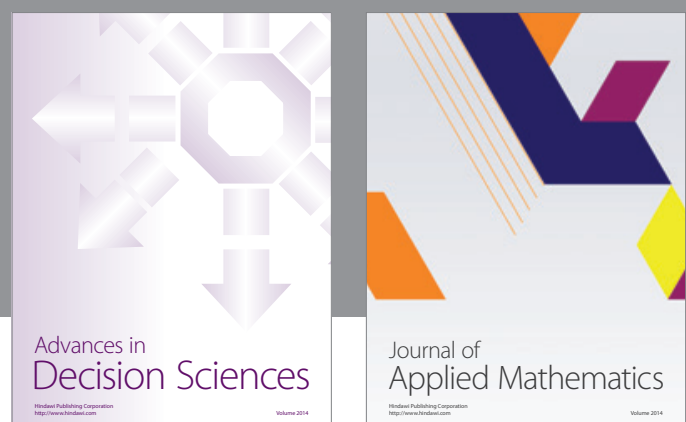

Journal of

Applied Mathematics
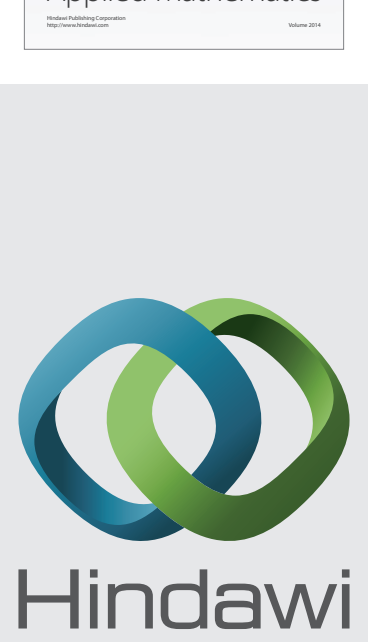

Submit your manuscripts at http://www.hindawi.com
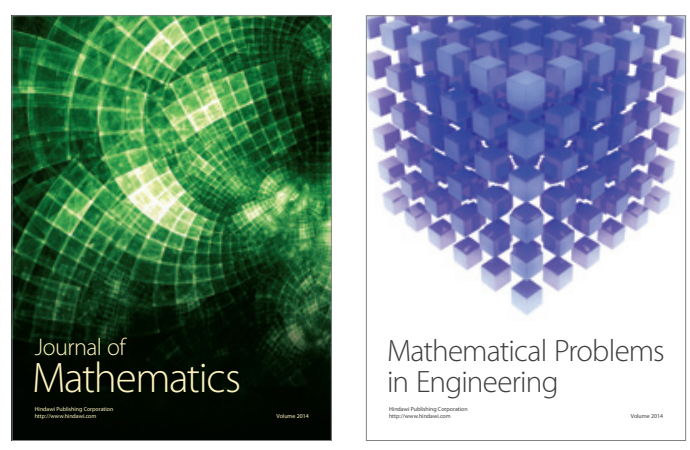

Mathematical Problems in Engineering
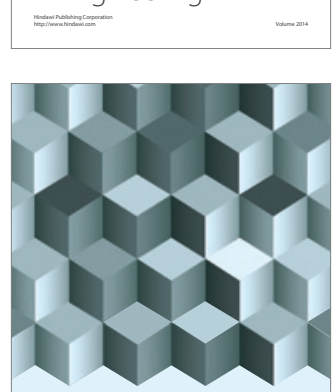

Journal of

Function Spaces
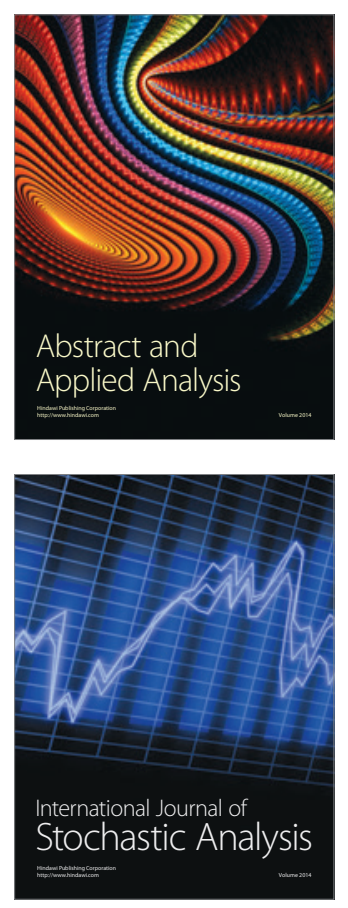

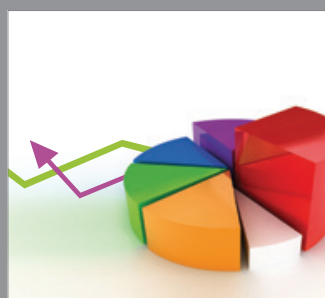

ournal of

Probability and Statistics

Promensencen
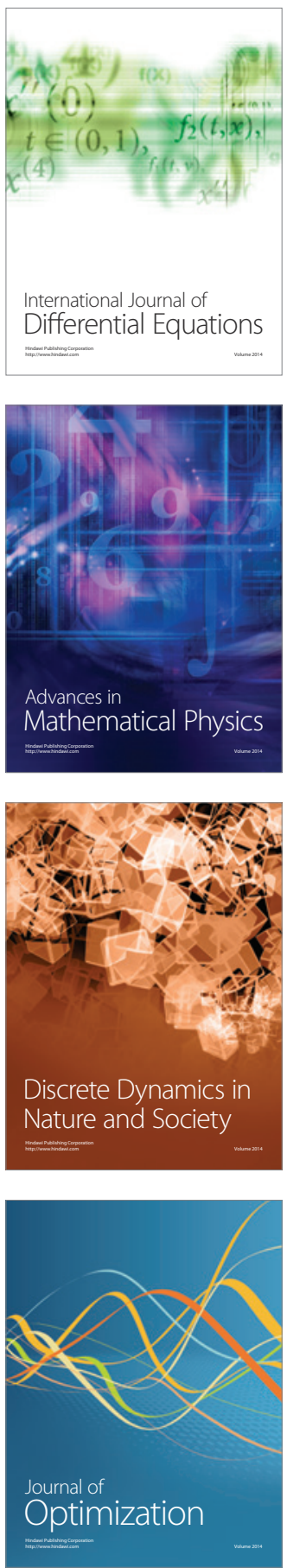